\title{
Benzimidazole Derivatives as Copper Alloy Corrosion Inhibitors
}

\author{
Martina Mumelaš, Helena Otmačić Ćurković,* Dajana Mikić, Marijana Hranjec, Maja Cindrić
}

\author{
Faculty of Chemical Engineering and Technology, University of Zagreb, Marulićev trg 19, HR-10000 Zagreb, Croatia \\ * Corresponding author's e-mail address: helena.otmacic@fkit.hr
}

RECEIVED: November 30, 2018 * REVISED: March 11, 2019 * ACCEPTED: March 12, 2019

PRoceEding OF THE $5^{\text {Th }}$ DAY OF Electrochemistry AND $8^{\text {Th }}$ ISE SSRSE, 25 May 2018, Zagreb, CroAtiA

\begin{abstract}
Seawater is a corrosive medium that adversely affects on the metallic structures. For that reason, it is often desirable to use some type of corrosion protection to extend the life of structures. The aim of this work was to examine the possibility of CuNi alloy protection in artificial seawater by four benzimidazole derivatives: 2-amino-5(6)nitrobenzimidazole, 2-amino-5-(6)-cyanobenzimidazole, 2-aminobenzimidazole, 2-amino-5(6)-(2-imidazolinyl)benzimidazole hydrochloride. The corrosion studies conducted by polarization measurements after $1 \mathrm{~h}$ of immersion in inhibitor solution showed that the most effective inhibitor is 2-amino-5(6)-nitrobenzimidazole. The electrochemical tests were also performed in time by the means of electrochemical impedance spectroscopy for the two most effective inhibitors. The surface of samples was analyzed by scanning electron microscopy and ATR-FTIR spectroscopy. It was concluded that the efficiency of studied inhibitors increases with prolonged exposure of the CuNi alloy to inhibitor solutions as well as with the increase of inhibitor concentration.
\end{abstract}

Keywords: 2-aminobenzimidazole, corrosion inhibitor, chloride, electrochemical impedance spectroscopy, polarization measurements, CuNi alloy.

\section{INTRODUCTION}

$S$ EAWATER is an aggressive medium that can cause deterioration of metallic structures due to the corrosive action of chloride ions. Copper-nickel alloys (CuNi) have found wide application in seawater constructions. Although in contact with seawater surface of the alloy gets covered by an oxide layer, that increases its corrosion resistance, it is still desirable to use some kind of protection against aggressive chloride ions. ${ }^{[1,2]}$ The most commonly used method for reducing the corrosion rate in closed systems is the use of corrosion inhibitors. Corrosion inhibitors are substances that added in a small amounts in aggressive media can greatly reduce metal corrosion rate. Many previously used commercial corrosion inhibitors are attempted to be replaced by less toxic and more environmentally acceptable compounds. For example, chromates were previously widely used as very efficient corrosion inhibitors but their application is nowadays restricted due to their toxicity. ${ }^{[3-5]}$

Among the most effective compounds used to inhibit corrosion of copper alloys are organic compounds containing heteroatoms such as sulfur, nitrogen, phosphorus and oxygen, which can be explained by the presence of empty $\mathrm{d}$ orbitals in copper atoms that can form coordinating links with atoms having free electron pairs. ${ }^{[6]}$ Such compounds are azoles, amines or amino and carboxylic acids. ${ }^{[7-18]}$ Benzotriazole (BTA) is one of the most important corrosion inhibitors for copper and its alloys, especially in a chloride containing environment. ${ }^{[7,10,13,14]}$ Due to the concerns about benzotriazole toxicity, research is increasingly focusing on finding environmentally friendly corrosion inhibitors that effectively protect copper. Among the examined environmentally friendly compounds are imidazole and its derivatives. ${ }^{[7-12,14,16-18]}$

While plain imidazole is not a particularly efficient corrosion inhibitor, some of its derivatives show higher inhibiting efficiencies. For example, it was found that imidazole efficiency in inhibiting copper corrosion in $3 \%$ $\mathrm{NaCl}$ solution is about $50 \%$, while efficiency of 1-phenyl-4methyl imidazole is $94 \% .{ }^{[16]}$ One of the promising imidazole compounds is benzimidazole. The benzimidazole molecule shows two modes of attachment to the metal surface:

(c) Br Br 
through a nitrogen atom with a solitary $\mathrm{sp}^{2}$ electron pair and through an aromatic ring. ${ }^{[11,17,19,20]}$ Benzimidazole and its derivatives are organic bases (donors of electrons), but the presence of an amino group also determines their acidic properties.[21]

The use of benzimidazole and its derivatives as corrosion inhibitors was examined in various media. Research by G. Lewis ${ }^{[22]}$ showed that inhibition of copper corrosion is caused by the formation of $\mathrm{Cu} /$ benzimidazole complex on a metal surface. E. Gutierrez et al. ${ }^{[23]}$ examined the inhibitory effect of several molecules from the group of imidazole and benzimidazole derivatives on carbon steel corrosion in $1.0 \mathrm{M} \mathrm{HCl}$. They have shown that the presence of halogens in the inhibitor structure promotes corrosion inhibition efficiency.

Benzimidazoles are known as a very important structural motifs and pharmacophores in medicinal chemistry and are incorporated in many biologically important molecules. ${ }^{[24]}$ 2-aminobenzimidazoles are usually the main precursors for the synthesis of targeted benzimidazole derivatives which exhibits promising biological activity such as antitumor, antibacterial or antioxidative activity. Thus, recently the benzimidazolyl substituted 2-carboxamides bearing either amidino, cyano or amino groups placed at the benzimidazole nuclei, displayed strong antiproliferative activity being also a promising antioxidants. ${ }^{[25,26]}$ The possibility of using 2-aminobenzimidazole as corrosion inhibitor was examined mainly on steel in acidic media[27-30] and neutral chloride solutions ${ }^{[31]}$. Recently, studies have been also conducted on copper in $3 \% \mathrm{NaCl}$ solution ${ }^{[18]}$. It was found that the high level of corrosion protection can be obtained after longer exposure of copper to inhibitor containing solution. In this work, the possibility of CuNi alloy protection using nontoxic 2-aminobenzimidazole and its derivatives synthesized at the Faculty of Chemical Engineering and Technology University of Zagreb is investigated. Corrosion studies are performed by electrochemical techniques in simulated seawater ( $3 \% \mathrm{NaCl}$ solution) as well as spectroscopic (FTIR) and microscopic (SEM) surface analysis.

\section{EXPERIMENTAL}

Four benzimidazole compounds examined as corrosion inhibitors of copper-nickel alloy Cu70Ni30 (CuNi): 2-amino5(6)-nitrobenzimidazole (ANB), 2-amino-5(6)-cyanobenzimidazole (ACB), 2-aminobenzimidazole (AB) and 2-amino-5(6)(2-imidazolinyl) benzimidazole hydrochloride $(A B C l)$, are presented in Figure 1. Among studied compounds 2-aminobenzimidazole $(A B)$ was purchased from Sigma Aldrich, while three other compounds where synthesised at Faculty of Chemical Engineering and Technology, University of Zagreb, according to previously published procedures. ${ }^{[25,32]}$<smiles>Nc1nc2cc([N+](=O)[O-])ccc2[nH]1</smiles>

b) $\mathrm{NC}^{\prime}$<smiles>Cc1ccc2[nH]c(N)nc2c1</smiles>

c)<smiles>Nc1nc2ccccc2[nH]1</smiles>

d)<smiles>Nc1nc2cc(C3=[NH+]CCN3)ccc2[nH]1</smiles>

Figure 1. Molecule structures of studied benzimidazoles: a) 2-amino-5(6)-nitrobenzimidazole (ANB); b) 2-amino-5(6)cyanobenzimidazole (ACB); c) 2-aminobenzimidazole (AB); d) 2-amino- 5(6)-(2-imidazolinyl) benzimidazole hydrochloride $(A B C l)$.

Cupronickel alloy rod ( $\mathrm{Cu} 70 \%-\mathrm{Ni} 30 \%$ ) with a $1.3 \mathrm{~cm}$ diameter was obtained from Goodfellow Inc., UK. In order to prepare working electrodes, CuNi rod was cut-out in $0.5 \mathrm{~cm}$ thick samples and on their back side a copper wire was soldered. At the end they were embedded into epoxy resin and the exposed surface of the working electrode was $1.33 \mathrm{~cm}^{2}$. Prior to performing electrochemical measurements, the CuNi samples were machine-grinded with granular grinding paper 800, 1200, 2500 and finally polished with $\alpha-\mathrm{Al}_{2} \mathrm{O}_{3}$ particle size $0.1 \mu \mathrm{m}$ to achieve mirror-like surface. After polishing, the samples were cleaned with ethanol in the ultrasonic bath for two minutes to remove any metallic dust and polishing residues. The samples were then washed with water and finally with deionised water.

The electrochemical investigations were conducted in a three electrode cell, in a solution simulating seawater, $3 \% \mathrm{NaCl}$. A platinum foil and saturated calomel electrode (SCE) were used as the counter and reference electrode, respectively. The polarization measurements were performed in the $\pm 150 \mathrm{mV} v$ s. open circuit potential potential $\left(E_{\text {ocp}}\right)$ range, at a potential scan rate of $0.166 \mathrm{mV} \mathrm{s}^{-1}$. The electrochemical impedance spectroscopy (EIS) was performed at the open circuit potential in the frequency range $100 \mathrm{kHz}$ to $10 \mathrm{mHz}$ with a $10 \mathrm{mV}_{\mathrm{rms}}$ amplitude. The electrochemical measurements were performed using a Bio-Logic SP-300 potentiostat. All tests were performed on a minimum of three samples to verify the repeatability of the results.

In addition to electrochemical studies, scanning electron microscopy (SEM) studies were performed to examine the surface morphology of the samples, after 7 days of exposure to corrosive media with or without the addition of studied corrosion inhibitors, by VEGA 3 SEM TESCAN at an acceleration voltage of $20 \mathrm{kV}$. The FTIR measurements were carried out using Attenuated Total Reflectance method (ATR-FTIR) on a Perkin-Elmer Spectrum One FTIR 
spectrometer, with the scan range from $4000-650 \mathrm{~cm}^{-1}$, having a resolution of $0.5 \mathrm{~cm}^{-1}$. Studies were also conducted on the selected samples after 7 days of exposure to $3 \% \mathrm{NaCl}$ with studied inhibitors in order to confirm adsorption of inhibitors on the alloy surface.

\section{RESULTS AND DISCUSSION}

\section{Polarization Measurements}

Polarization measurements were conducted after $1 \mathrm{~h}$ of CuNi electrode immersion in chloride solution with or without the addition of studied corrosion inhibitors. Studies were conducted at different inhibitor concentrations in order to determine the influence of concentration on inhibitor efficiency. Figures 2, 3, 4 and 5 show the polarization curves of CuNi alloys in simulated seawater without and with the addition of tested inhibitors at different concentrations ( $0.1 \mathrm{mM}, 0.5 \mathrm{mM}, 1 \mathrm{mM})$. Tables $1-4$ present the corrosion parameters obtained from the polarization curves by Tafel extrapolation method: corrosion potential $\left(E_{\text {corr }}\right)$, corrosion current density $\left(j_{\text {corr }}\right)$, anodic and cathodic Tafel slopes $\left(\beta_{a}\right.$ and $\left.\beta_{c}\right)$ and inhibiting efficiency $\left(\eta_{i}\right)$, calculated by equation 1 :

$$
\eta_{i}=\frac{j_{\text {corr }, 0}-j_{\text {corr }, i}}{j_{\text {corr }, 0}} \times 100 \%
$$

where $j_{\text {corr }, 0}$ and $j_{\text {corr }, i}$ represent corrosion current densities of blank and treated sample respectively.

From the polarization curves obtained for 2-amino5(6)-nitrobenzimidazole, shown in Figure 2, it is evident that in the presence of the ANB a significant decrease of cathodic currents occurs. With the increase in ANB concentration its influence on cathodic currents is increasing, while at the highest examined concentration, the effect on

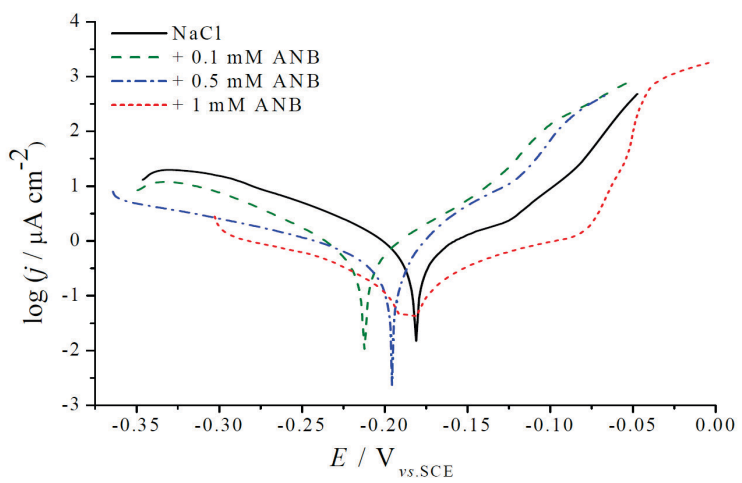

Figure 2. Polarization curves of CuNi alloy in $3 \% \mathrm{NaCl}$ without inhibitors and with addition of 2-amino-5(6)nitrobenzimidazole (ANB) at various concentrations. the anodic currents is also visible. The more pronounce effect of ANB inhibitor on the cathodic corrosion reaction than on anodic reaction is also seen from the value of $E_{\text {corr, }}$ which is in the presence of the inhibitor more negative than in the blank solution. From Table 1. it can be seen that the highest decrease in the corrosion current density $j_{\text {corr, }}$ occurs at the highest inhibitor concentration, $1 \mathrm{mM}$. It is assumed that this is due to the fact that in a more concentrated solution a more compact inhibitor film is formed, which reduces the $\mathrm{O}_{2}$ reduction because the

Table 1. Corrosion parameters determined by the Tafel extrapolation method for CuNi in blank $3 \% \mathrm{NaCl}$ solution and with addition of ANB.

\begin{tabular}{ccccc}
\hline$c$ (inh) $/ \mathrm{mmol} \mathrm{dm}^{-3}$ & 0 & 0.1 & 0.5 & 1 \\
\hline$E_{\text {corr }} / \mathrm{mV}$ & $-180 \pm 12$ & $-205 \pm 5$ & $-183 \pm 15$ & $-203 \pm 15$ \\
$\beta_{a} / \mathrm{mV} \mathrm{dec}^{-1}$ & $81 \pm 39$ & $54 \pm 4$ & $34 \pm 3$ & $92 \pm 57$ \\
$-\beta_{c} / \mathrm{mV} \mathrm{dec}^{-1}$ & $78 \pm 5$ & $68 \pm 1$ & $60 \pm 11$ & $88 \pm 13$ \\
$j_{\text {corr' }} / \mu \mathrm{A} \mathrm{cm}{ }^{-2}$ & $0.65 \pm$ & $0.49 \pm$ & $0.22 \pm$ & $0.19 \pm$ \\
$\eta / \%$ & 0.04 & 0.02 & 0.09 & 0.10 \\
\hline
\end{tabular}

Table 2. Corrosion parameters determined by the Tafel extrapolation method for $\mathrm{CuNi}$ in blank $3 \% \mathrm{NaCl}$ solution and with addition of ACB.

\begin{tabular}{ccccc}
\hline$c$ (inh) $/ \mathrm{mmol} \mathrm{dm}^{-3}$ & 0 & 0.1 & 0.5 & 1 \\
\hline$E_{\text {corr }} / \mathrm{mV}$ & $-180 \pm 12$ & $-223 \pm 8$ & $-206 \pm 10$ & $-213 \pm 20$ \\
$\beta_{a} / \mathrm{mV} \mathrm{dec}^{-1}$ & $81 \pm 39$ & $58 \pm 6$ & $42 \pm 5$ & $35 \pm 4$ \\
$-\beta_{c} / \mathrm{mV} \mathrm{dec}^{-1}$ & $78 \pm 5$ & $71 \pm 9$ & $88 \pm 8$ & $59 \pm 6$ \\
$j_{\text {corr' }} / \mu \mathrm{A} \mathrm{cm}{ }^{-2}$ & $0.65 \pm$ & $0.60 \pm$ & $0.53 \pm$ & $0.41 \pm$ \\
$\eta / \%$ & 0.04 & 0.06 & 0.12 & 0.06 \\
\hline
\end{tabular}

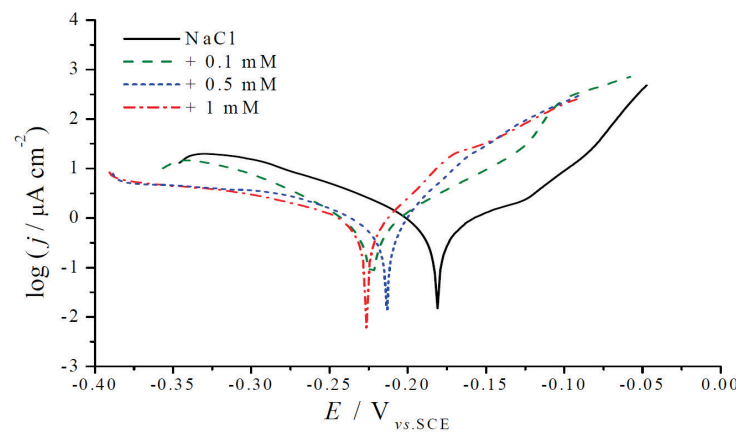

Figure 3. Polarization curves of CuNi alloy in $3 \% \mathrm{NaCl}$ without inhibitors and with addition of 2-amino-5(6)cyanobenzimidazole (ACB) at different concentrations. 
surface is blocked. The highest obtained inhibiting efficiency is $71 \%$. Although it has been found that an increase in concentration of the inhibitor results in an increase in its efficiency, studies have not been conducted at higher concentrations due to ANB limited water solubility. The similar situation is with other studied benzimidazole derivatives, as all of them have low water solubility, around $1 \mathrm{mM}$.

From the polarization curves gained for 2-amino5(6)-cyanobenzimidazole shown in Figure 3 , it can be seen that this inhibitor, like ANB, decreases the cathodic currents of CuNi and that this effect becomes more important with the increase of inhibitor concentration. The influence on cathodic currents is also seen from the values of $E_{\text {corr }}$ which are more negative than that obtained for an uninhibited system. Unlike ANB, this inhibitor doesn't show anodic inhibition effect. From Table 2. it can be seen that the highest decrease in the $j_{\text {corr }}$ occurred the highest concentration of inhibitor, $1 \mathrm{mM}$. However the maximum obtained corrosion inhibition efficiency is only $37 \%$.

From the polarization curves for the 2-aminobenzimidazole inhibitor shown in Figure 4, it is apparent that in the presence of this inhibitor there is a slight decrease in the cathodic current (more pronounced with the increase in the concentration of the inhibitor) but at the

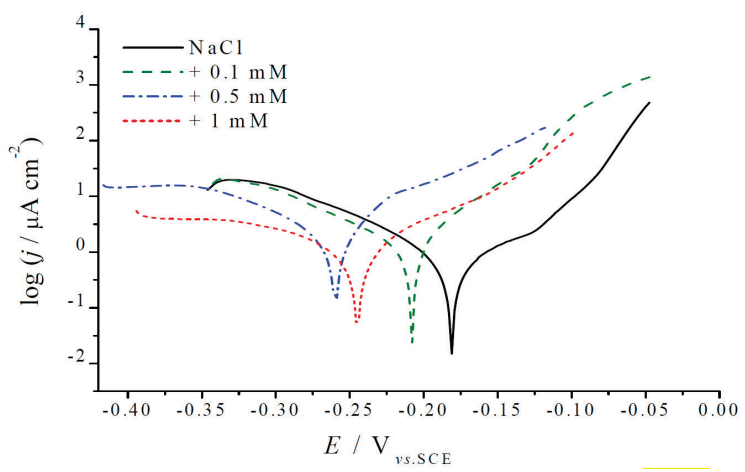

Figure 4. Polarization curves of CuNi alloy in $3 \% \mathrm{NaCl}$ without inhibitors and with addition of 2-aminobenzimidazole $(A B)$ at different concentrations.

Table 3. Corrosion parameters determined by the Tafel extrapolation method for $\mathrm{CuNi}$ in blank $3 \% \mathrm{NaCl}$ solution and with addition of $A C B$.

\begin{tabular}{ccccc}
\hline$c$ (inh) $/ \mathrm{mmol} \mathrm{dm}^{-3}$ & 0 & 0.1 & 0.5 & 1 \\
\hline$E_{\text {corr }} / \mathrm{mV}$ & $-180 \pm 12$ & $-212 \pm 4$ & $-260 \pm 5$ & $-241 \pm 16$ \\
$\beta_{a} / \mathrm{mV} \mathrm{dec}^{-1}$ & $81 \pm 39$ & $49 \pm 3$ & $37 \pm 5$ & $56 \pm 21$ \\
$-\beta_{c} / \mathrm{mV} \mathrm{dec}^{-1}$ & $78 \pm 5$ & $73 \pm 9$ & $62 \pm 3$ & $79 \pm 5$ \\
$j_{\text {corr }} / \mu \mathrm{A} \mathrm{cm} \mathrm{cm}^{-2}$ & $0.65 \pm$ & $1.06 \pm$ & $1.33 \pm$ & $0.70 \pm$ \\
$\eta / \%$ & 0.04 & 0.16 & 0.09 & 0.29 \\
\hline
\end{tabular}

same time an increase in the anodic currents is observed. From Table 3, it can be seen that $A B$ has no significant inhibitory effect. At lower inhibitor concentrations $j_{\text {corr }}$ is even higher than that observed in the blank solution, suggesting that under these conditions the $A B$ acts as a corrosion activator. Only at higher $\mathrm{AB}$ concentrations $j_{\text {corr }}$ approaches values obtained for the sample that was exposed only to the simulated seawater solution.

From the polarization curve for the 2-amino-5(6)-(2imidazolinyl)benzimidazole hydrochloride inhibitor shown in Figure 5, it is apparent that this inhibitor, like other three, significant influences only on cathodic currents and that this influence increases with increasing its concentration. The influence on cathodic currents is also noted from the value of $E_{\text {corr, }}$ which is more negative than in blank solution. Table 4. shows that the highest efficiency of the inhibitor is at the concentration $0.5 \mathrm{mM}$ and is $28 \%$.

Results obtained by polarisation measurements show that studied inhibitors adsorb on the alloy surface and primary act as cathodic corrosion inhibitors for CuNi alloy. Anodic inhibition effect, on the other hand, depends on the chemical structure of organic molecule. In case of ANB inhibitor, in its highest concentration it acts as mixed

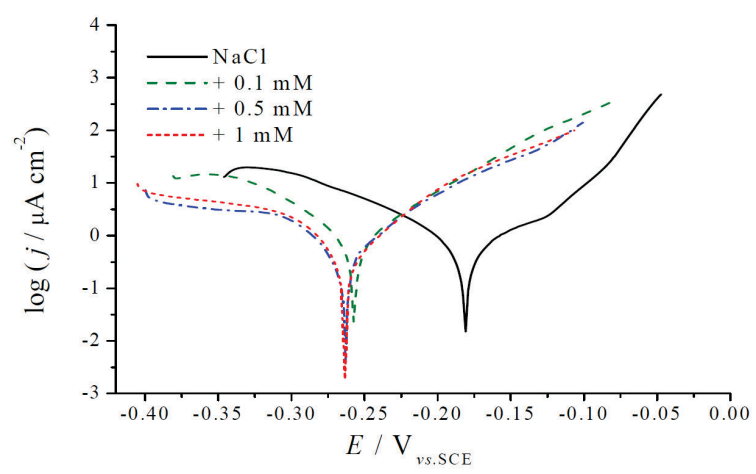

Figure 5. Polarization curves of CuNi alloy in $3 \% \mathrm{NaCl}$ without inhibitors and with addition of 2-amino-5(6)-(2imidazolinyl)benzimidazole hydrochloride $(\mathrm{ABCl})$ at various concentrations.

Table 4. Corrosion parameters determined by the Tafel extrapolation method for CuNi in blank $3 \% \mathrm{NaCl}$ solution and with addition of $\mathrm{ABCl}$.

\begin{tabular}{ccccc}
\hline$c($ inh $) / \mathrm{mmol} \mathrm{dm}^{-3}$ & 0 & 0.1 & 0.5 & 1 \\
\hline$E_{\mathrm{corr}} / \mathrm{mV}$ & $-180 \pm 12$ & $-260 \pm 5$ & $-260 \pm 5$ & $-266 \pm 9$ \\
$\beta_{a} / \mathrm{mV} \mathrm{dec}^{-1}$ & $81 \pm 39$ & $58 \pm 8$ & $52 \pm 8$ & $51 \pm 5$ \\
$-\beta_{c} / \mathrm{mV} \mathrm{dec}^{-1}$ & $78 \pm 5$ & $59 \pm 4$ & $63 \pm 5$ & $60 \pm 13$ \\
$j_{\mathrm{corr}} / \mu \mathrm{A} \mathrm{cm}{ }^{-2}$ & $0.65 \pm$ & $0.78 \pm$ & $0.47 \pm$ & $0.54 \pm$ \\
$\eta / \%$ & 0.04 & 0.12 & 0.07 & 0.09 \\
& - & - & $28 \pm 11$ & $16 \pm 14$ \\
\hline
\end{tabular}


corrosion inhibitor, while $A B$ shows negative effect - higher values of corrosion current densities, i.e. corrosion activation. This can be explained by the fact that inhibitor addition leads to lowering of cathodic current densities but also to increase of anodic current densities. When the lowering of the cathodic current is much more pronounced than the increase of anodic current, the resulting corrosion current densities are lower than in the blank solution and corrosion inhibition is achieved.

Our study shows that substituents on the molecule of 2-aminobenzimidazole significantly influence on its inhibitory properties. Taking into account that the electron density is very important and affects the strength of the adsorption band by any mechanism, various substituents placed at the aromatic and heteroaromatic nuclei can strongly influenced electron density and thus, corrosion inhibiting properties. The inhibition effect can be determined either by mesomeric, inductive and steric effects of the substituents. When benzimidazole nuclei is substituted with an electron-withdrawing group like nitro or cyano, the electron density was drawn away which may lead to a decrease in electron density on the nitrogen atoms.

The corrosion inhibition of benzimidazole derivatives could be based on the adsorption onto metal surfaces through the nitrogen atoms. Within the decrease of electron density caused by electron-withdrawing effect, the nitrogen atoms of imidazole ring are not hindered and could take place in the adsorption process. Furthermore, the nitro group placed at the benzene nuclei also affect the acidity and thus, this type of compound is strongly dissociated in solution. The enhancement of the protective properties of nitrosubstituted benzimidazoles in comparison to cyano substituted derivatives could be observed becuase of the formation of an ionic bond between inhibitor and metal. Amidino substituted benzimidazole is protonated and thus, it's interaction with positively charged metal surface is restricted which is also confirmed experimentally showing very low inhibition properties of $\mathrm{ABCl}$ derivative. Obtained results are in good agreement with some previously published results. ${ }^{[22]}$
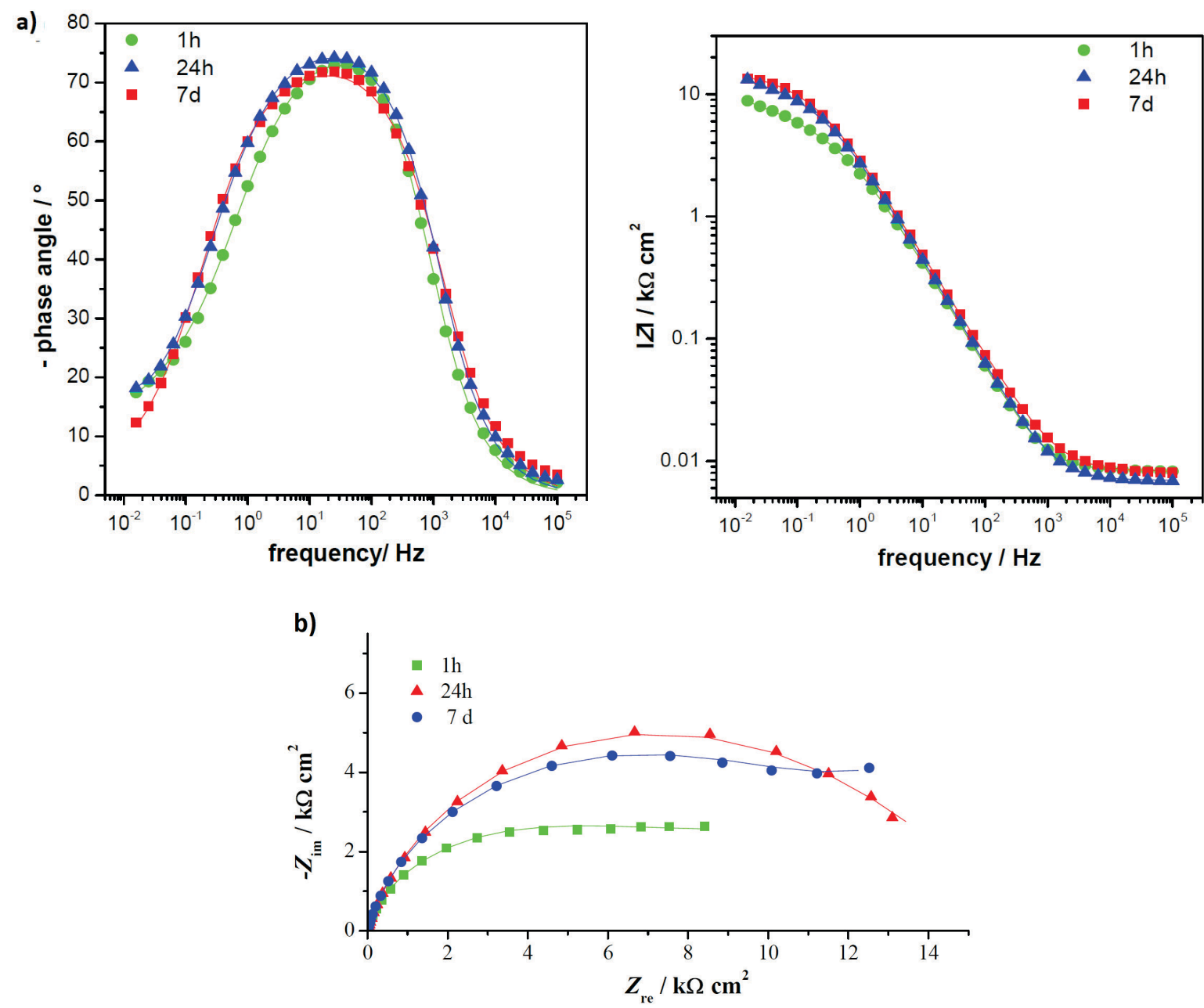

Figure 6. EIS spectra of CuNi alloy in $3 \% \mathrm{NaCl}$ without inhibitors: a) Bode and b) Nyquist plot. 
Polarization measurements were conducted after only one hour of $\mathrm{CuNi}$ exposure to $3 \% \mathrm{NaCl}$ solution, blank or with addition of studied benzimidazoles. However, studies on 2-aminobenzimidazole on copper showed that its inhibiting efficiency increases in time. ${ }^{[18]}$ In order to verify if longer exposure of CuNi alloy to chloride solution containing inhibitors would lead to formation of more protective inhibitor film, studies in time were conducted by electrochemical impedance spectroscopy for the two most promising compounds, i.e. ANB and ACB.

\section{Electrochemical Impedance Spectroscopy (EIS)}

In Figures 6, 7 and 8, are shown impedance spectra for $\mathrm{CuNi}$ alloy in $3 \% \mathrm{NaCl}$, without and with the addition of ANB and ACB.

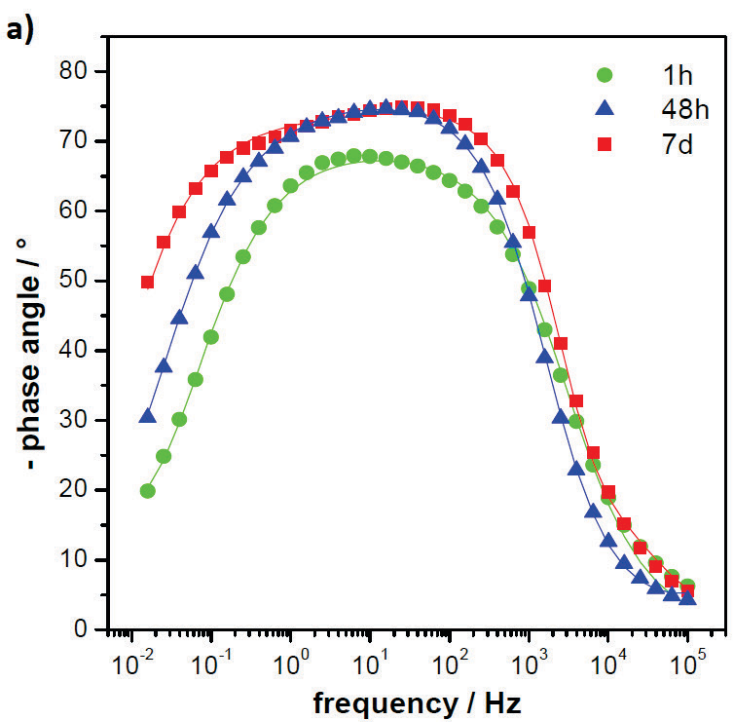

The results obtained by electrochemical impedance spectroscopy can be represented by an equivalent electric circuit (Figure 9) where $R_{\mathrm{el}}$ represents the resistance of the electrolyte, the $R_{\mathrm{f}}$ resistance of the oxide or the inhibitor film, $Q_{\mathrm{f}}$ a constant phase element that describes the capacitive behaviour of the surface layer of oxide or inhibitor, $R_{\mathrm{ct}}$ charge transfer resistance and $Q_{\mathrm{dl}}$ a constant phase element that refers to the capacitance of the double layer.

Coefficients $n_{\mathrm{f}}$ and $n_{\mathrm{dl}}$ are related to deviation from ideal capacitive behaviour.

Parameters of the proposed electric model were estimated by using the Zsimp Win program, which is based on the simplex method. Good agreement between experimental data (points) and data calculated from the model (lines) can be observed in Figures $6-8$. The obtained impedance parameters are given in Table 5 .

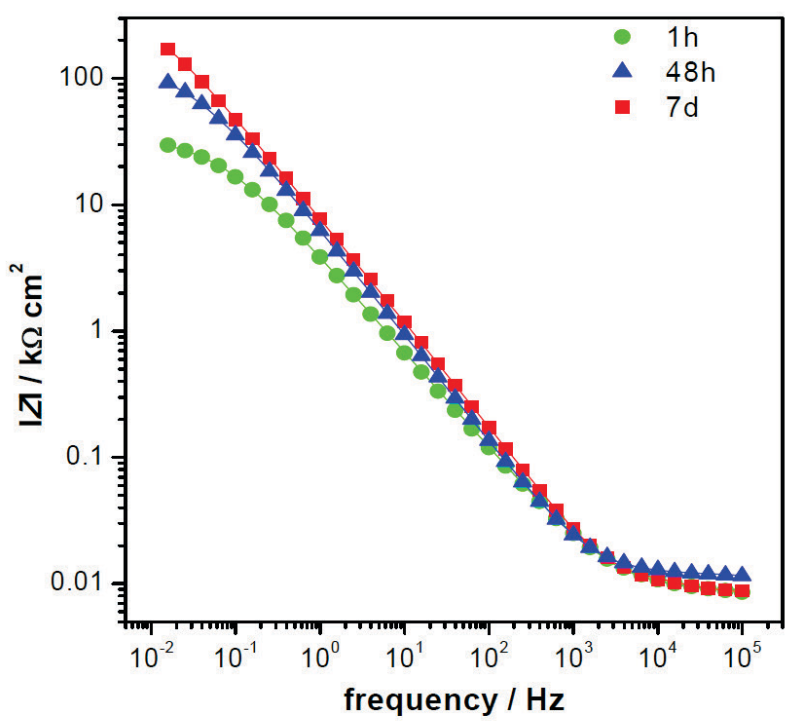

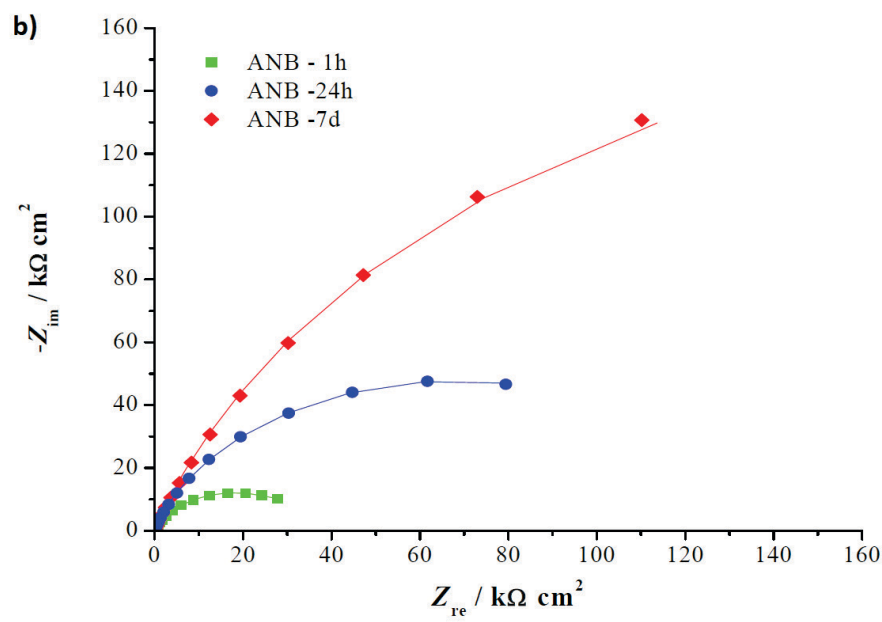

Figure 7. EIS spectra of CuNi alloy in 3\% NaCl with the addition of $1 \mathrm{mM}$ 2-amino-5 (6) -nitrobenzimidazole (ANB): a) Bode and b) Nyquist plot. 

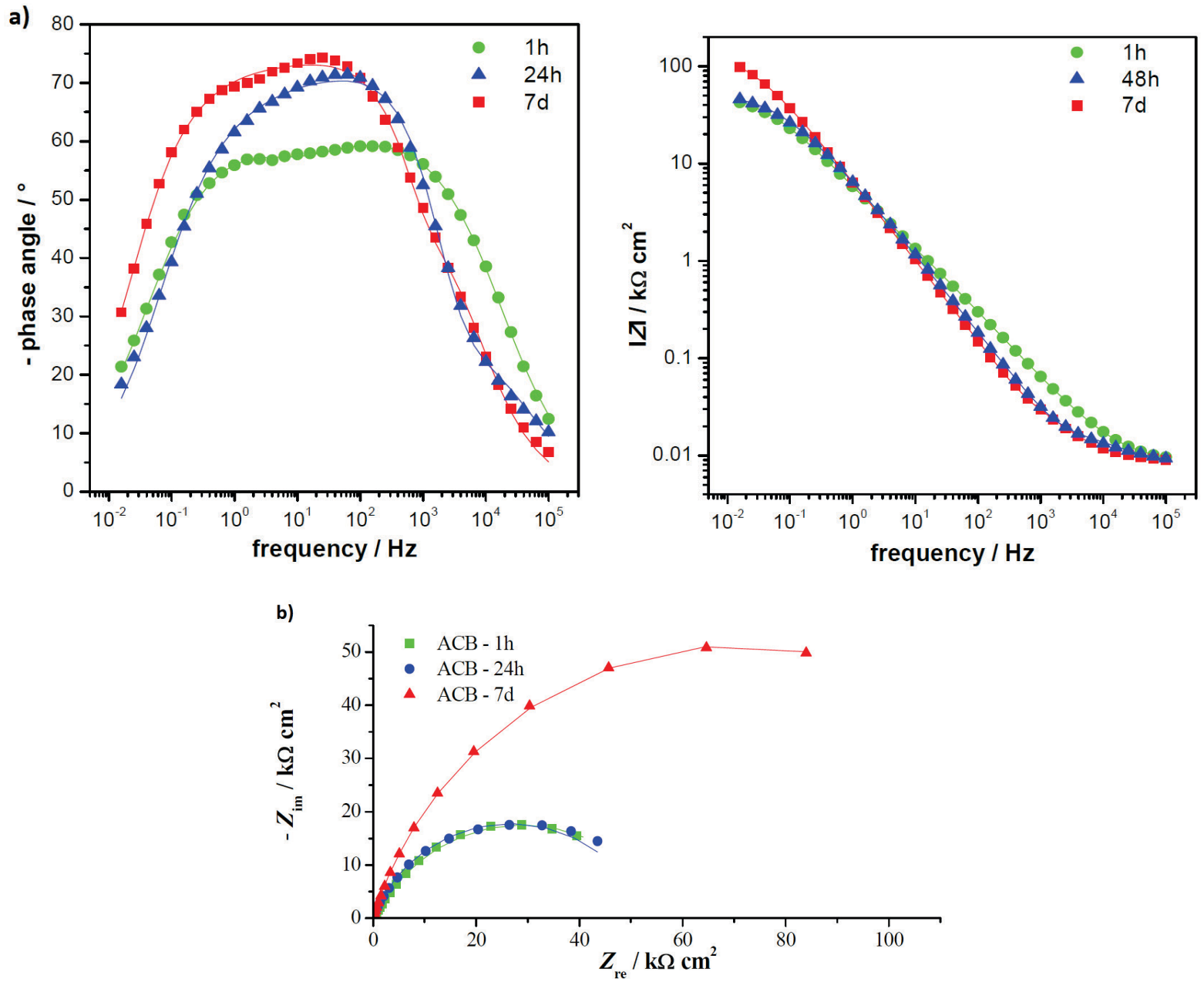

Figure 8. EIS spectra of CuNi alloy in $3 \% \mathrm{NaCl}$ with the addition of $0.5 \mathrm{mM} 2$-amino-5 (6) -cyanobenzimidazole (ACB): a) Bode and b) Nyquist plot.

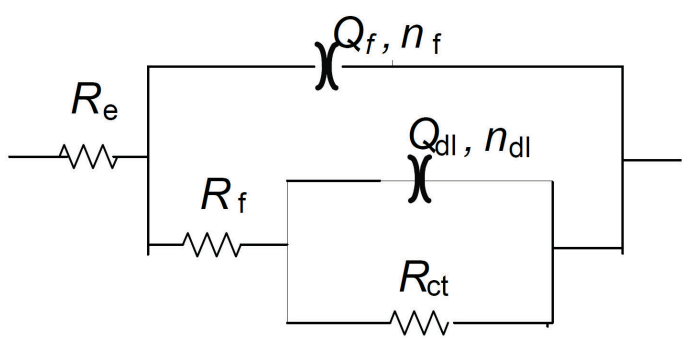

Figure 9. Equivalent electric circuit for CuNi in seawater used for analysis of impedance spectra.

Studies conducted by electrochemical impedance spectroscopy show that the impedance of samples exposed to blank $3 \% \mathrm{NaCl}$ slightly increases in time (Figure 6). Table 5 . shows that $R_{\mathrm{f}}$ values in seawater increase, due to the formation of corrosion product layer on CuNi alloy surface. The charge transfer resistance initially increases which can be attributed to the effect of the resulting oxide, but after
Table 5. Impedance parameters obtained by modelling EIS spectra presented in Figures 6-8 with the electrical equivalent circuit given in Figure 9.

\begin{tabular}{|c|c|c|c|c|c|c|}
\hline Sample & $\begin{array}{c}Q_{f} / \\
\mu S s^{n} \mathrm{~cm}^{-2}\end{array}$ & $n_{f}$ & $\begin{array}{c}R_{f} / \\
\mathrm{k} \Omega \mathrm{cm}^{2}\end{array}$ & $\begin{array}{c}Q_{d l} / \\
\mu S s^{n} \mathrm{~cm}^{-2}\end{array}$ & $n_{d l}$ & $\begin{array}{c}R_{c t} / \\
\mathrm{k} \Omega \mathrm{cm}^{2} \\
\end{array}$ \\
\hline $\mathrm{NaCl}-1 \mathrm{~h}$ & 85.7 & 0.87 & 2.68 & 353 & 0.50 & 6.93 \\
\hline $\mathrm{NaCl}-48 \mathrm{~h}$ & 86.7 & 0.86 & 6.37 & 486 & 0.60 & 7.47 \\
\hline $\mathrm{NaCl}-7 \mathrm{~d}$ & 89.9 & 0.83 & 7.80 & 332 & 0.50 & 4.32 \\
\hline$A N B-1 h$ & 61.4 & 0.77 & 34.92 & 379 & 0.99 & 13.00 \\
\hline$A N B-48 h$ & 42.1 & 0.85 & 29.95 & 16.6 & 0.62 & 70.38 \\
\hline$A N B-7 d$ & 26.9 & 0.80 & 0.01 & 2.50 & 0.99 & 416.1 \\
\hline$A C B-1 h$ & 36.0 & 0.70 & 5.34 & 11.8 & 0.70 & 52.17 \\
\hline$A C B-48 h$ & 33.5 & 0.73 & 0.02 & 3.66 & 0.98 & 53.71 \\
\hline$A C B-7 d$ & 32.3 & 0.79 & 0.07 & 2.71 & 1.00 & 141.8 \\
\hline
\end{tabular}


7 days a drop in charge transfer resistance has been observed which is likely to result from damage of the oxide film caused by chloride ions.

For the sample exposed to simulated seawater with ANB (Figure 7), impedance increases in time, reaching the values much higher than those observed for the blank sample. From the value of impedance parameters (Table 5), it can be seen that in the solution containing ANB the film resistance $\left(R_{\mathrm{f}}\right)$ drops in time, while the charge transfer resistance $\left(R_{\mathrm{ct}}\right)$ increases. The augmentation of $R_{\mathrm{ct}}$ values is followed by a decrease in a constant phase element related to the double layer capacitance $\left(Q_{\mathrm{dl}}\right)$. The $Q_{\mathrm{dl}}$ drop is usually related to the adsorption of inhibitor, which concentration at the metal surface increases over time and simultaneously replaces the adsorbed water. Observed time variation of corrosion parameters leads to conclusion that ANB enhances dissolution of initially present layer of corrosion products ( $R_{\mathrm{f}}$ decrease), probably due to the formation of soluble complexes, but on the other hand adsorption of inhibitor on bare $\mathrm{Cu}$ surface leads to the formation of protective surface film.

For the sample exposed to the solution of $A C B$ (Figure 8), the impedance increased slightly in time, and it is the greatest after 7 days. From the values of impedance parameters (Table 5), obtained by fitting the experimental data to the selected equivalent current circuit, it can be seen that as well as for ANB inhibitor, the film resistance value $\left(R_{\mathrm{f}}\right)$ drops, while the charge transfer resistance value $\left(R_{\mathrm{ct}}\right)$ increases. The growth of $R_{\mathrm{ct}}$ values is followed by a decrease in the constant phase element value related to the double-layer capacitance $\left(Q_{\mathrm{dl}}\right)$. These results lead to the conclusion that $A C B$ inhibition mechanism is similar to that of ANB.

\section{Scanning Electron Microscopy (SEM)}

In addition to electrochemical measurements, the surface analysis was performed by scanning electron microscopy, thus obtaining insight into electrode surface condition. Studied samples were exposed for 7 days to blank $3 \% \mathrm{NaCl}$ solution (Figure 10.) and solution with ANB (Figure 11.) or ACB (Figure 12.)

SEM images of sample exposed to blank solution (Figure 10) show that corrosion products are present all over the CuNi surface, resulting from the aggressive action of chloride ions.

Figure 11 shows the surface of the sample exposed for 7 days to $3 \% \mathrm{NaCl}$ solution with ANB. It is apparent that the surface is homogeneous and without significant corrosion damage, even under high magnification, which confirms previous assumptions that a compact and protective inhibitor film is formed.

Figure 12 shows the surface of the sample exposed for 7 days to $3 \% \mathrm{NaCl}$ solution with $\mathrm{ACB}$. The presence of corrosion products is visible on part of the sample,while higher magnification image reveals the porosity of the surface film. Therefore it can be concluded that the inhibitor film is not fully covering the surface as in the case of ANB.
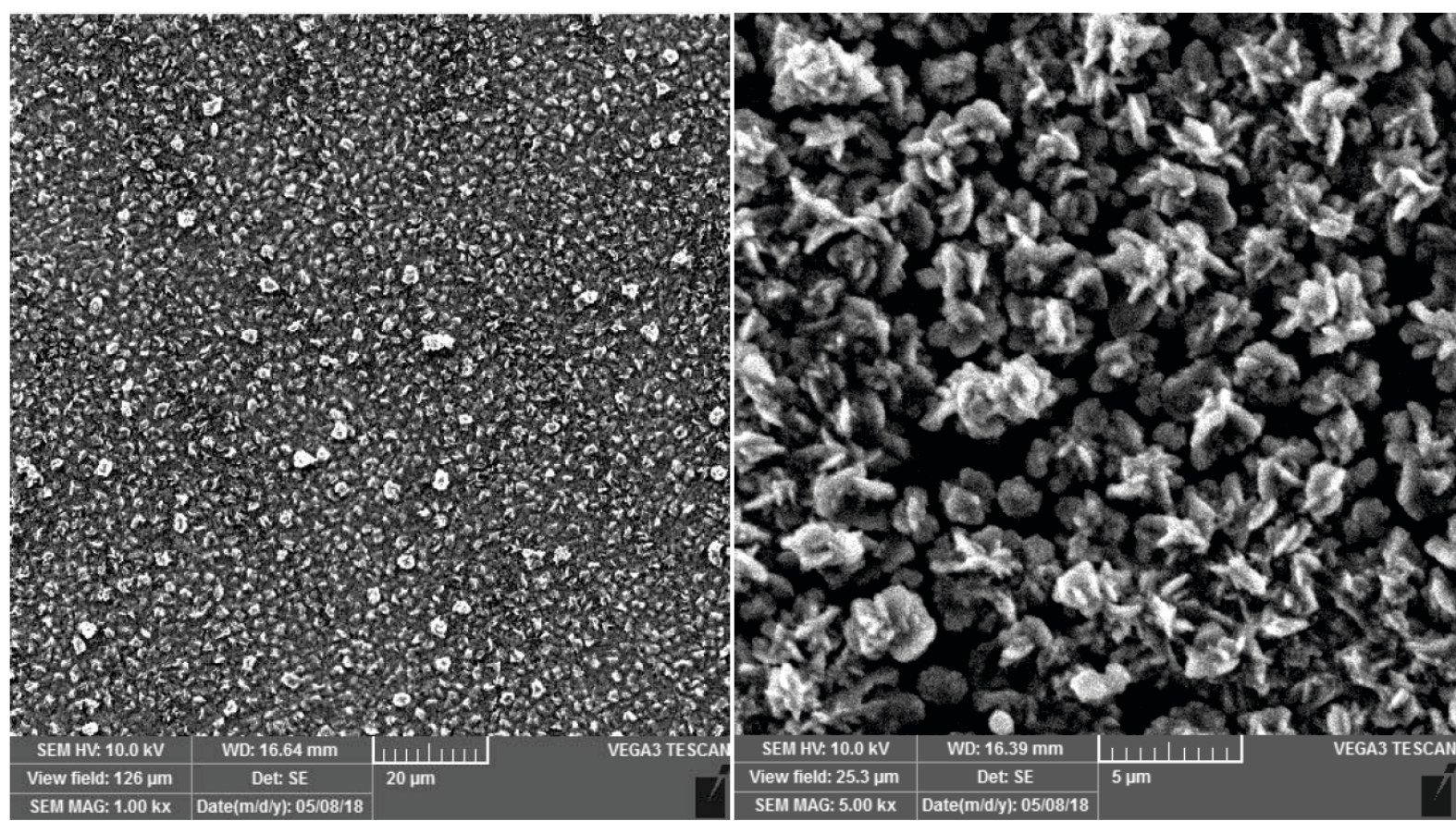

Figure 10. The SEM images of sample exposed to blank $3 \% \mathrm{NaCl}$ solution for 7 days. 

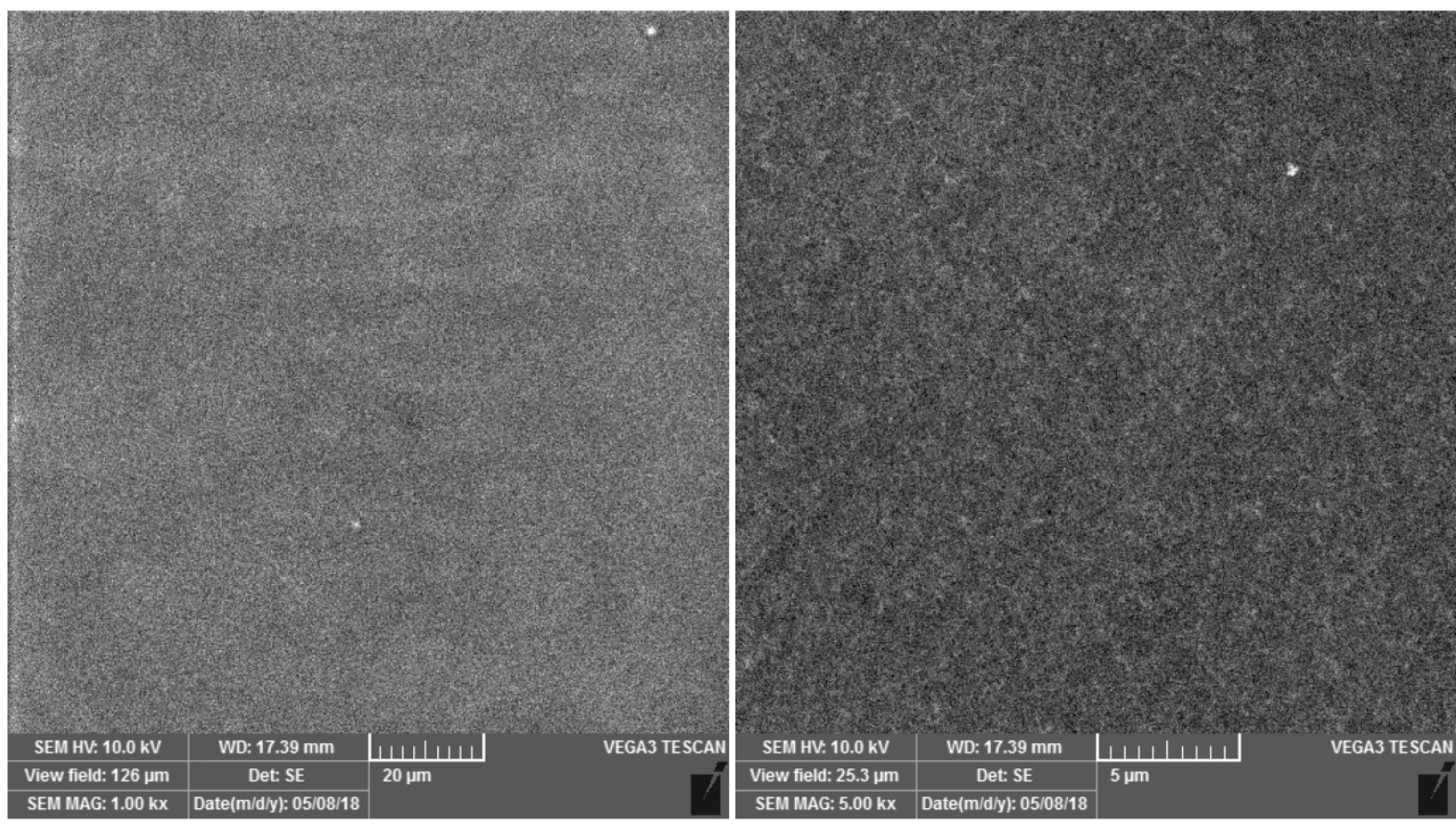

Figure 11. The SEM images of the sample exposed to $3 \% \mathrm{NaCl}$ solution with ANB for 7 days.
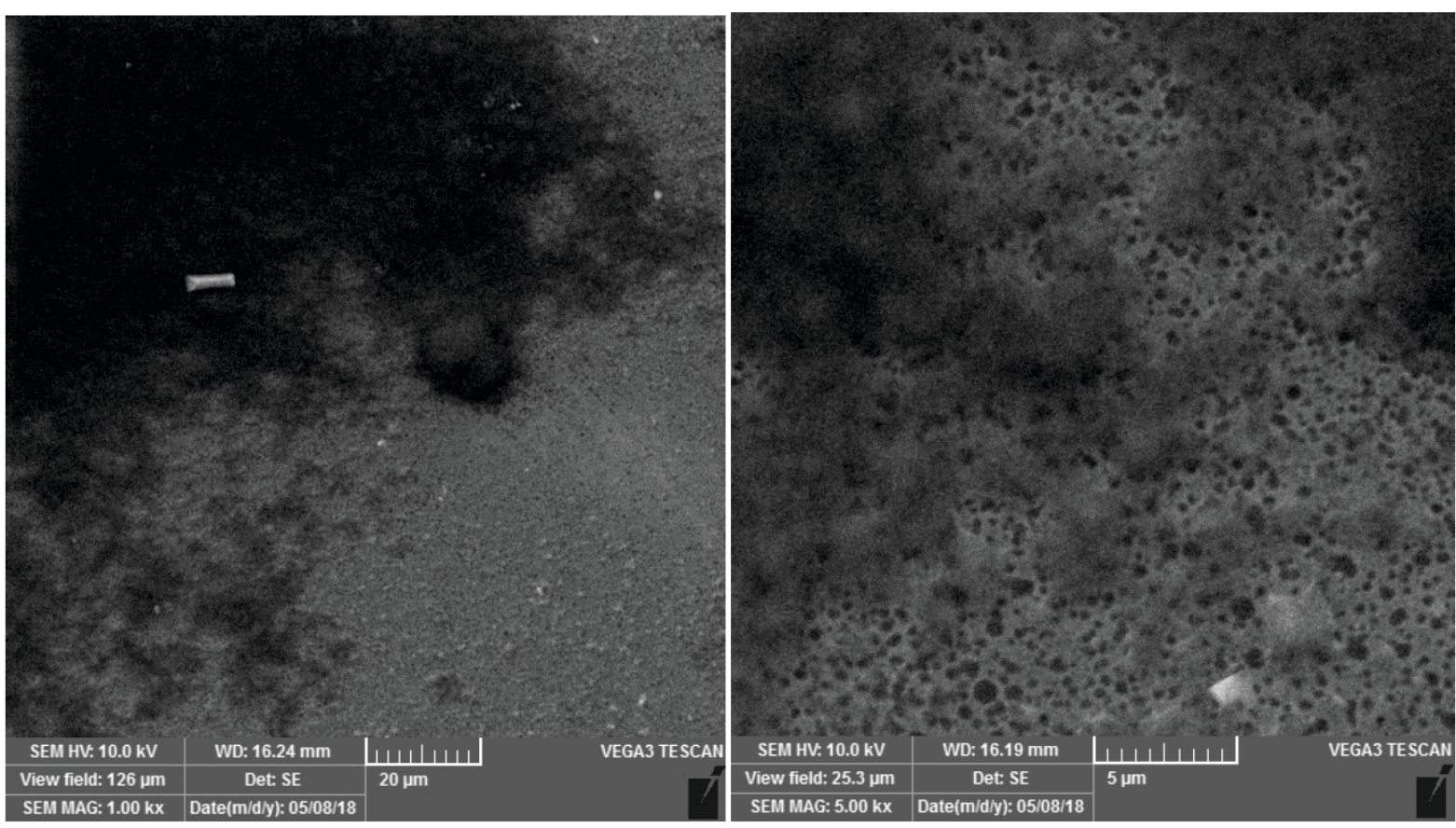

Figure 12. The SEM images of the sample exposed to $3 \% \mathrm{NaCl}$ solution with ACB for 7 days.

\section{FTIR Spectroscopy Studies}

In order to confirm binding of corrosion inhibitors onto the CuNi surface, samples were examined by the means of the FTIR spectroscopy.
The ATR-FTIR spectra of the surface of copper-nickel alloy in the presence of the 2-amino5(6)-nitrobenzimidazole and 2-amino-5(6)-cyanobenzimidazole are shown in Figures 13 and 14. The samples were exposed for 7 days to $3 \% \mathrm{NaCl}$ solution in which studied inhibitors were added. 


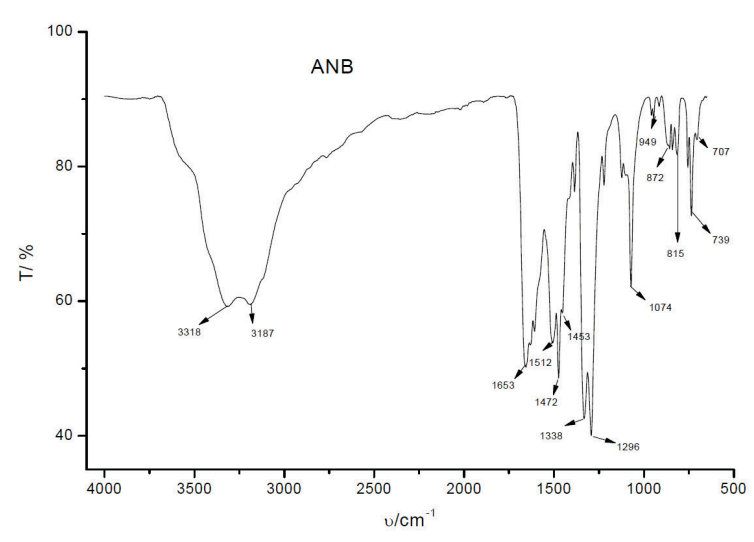

Figure 13. FTIR spectrum obtained for a sample exposed to 2-amino-5(6)-nitrobenzimidazole solution for 7 days.

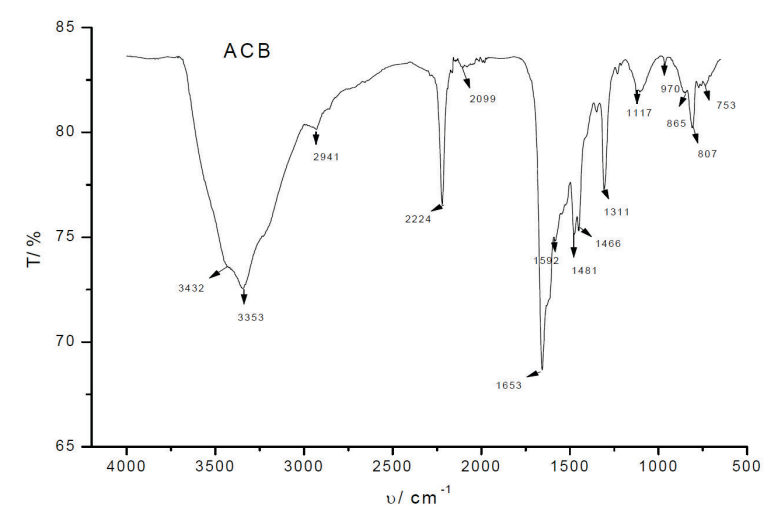

Figure 14. FTIR spectrum obtained for a sample exposed to (2-amino-5(6)-cyanobenzimidazole) solution for 7 days.

In Figure 16, the FTIR spectrum for the sample exposed to ANB is shown. The band characteristic of symmetric $\mathrm{N}-\mathrm{H}$ stretching at $3318 \mathrm{~cm}^{-1}$ and band characteristic for the amino $\left(\mathrm{NH}_{2} 1653 \mathrm{~cm}^{-1}\right)$ and nitro group $\left(\mathrm{NO}_{2} 1512 \mathrm{~cm}^{-1}\right)$ are present. The presence of characteristic vibration stretching of the $\mathrm{C}-\mathrm{H}$ group in the aromatic compounds is expressed as band at 3187 $\mathrm{cm}^{-1}$. The band at $1472 \mathrm{~cm}^{-1}$ corresponds to the vibration stretching of the $\mathrm{C}=\mathrm{C}$ group in the aromatic ring.

Figure 14 shows the FTIR spectrum for the sample exposed to ACB. The bands characteristic for asymmetric and symmetric stretching of the $\mathrm{N}-\mathrm{H}$ group at $3432 \mathrm{~cm}^{-1}$ and $3353 \mathrm{~cm}^{-1}$ are observed as well as the bands characteristic of the amino group $\left(\mathrm{NH}_{2}-1653 \mathrm{~cm}^{-1}\right)$ and the cyano group $\left(\mathrm{C} \equiv \mathrm{N}-2224 \mathrm{~cm}^{-1}\right)$. The band at $1466 \mathrm{~cm}^{-1}$ corresponds to $\mathrm{C}=\mathrm{C}$ vibrational stretching in the aromatic ring. The FTIR results confirm formation of protective films of the studied inhibitors.

\section{CONCLUSIONS}

Electrochemical studies show that the nature of the substituents on the molecule of 2-aminobenzimidazole significantly influence its inhibitory properties. Among studied inhibitors, the highest corrosion inhibition show 2-amino5(6)-nitrobenzimidazole and 2-amino-5(6)-cyanobenzimidazole. In general, inhibiting efficiency of the test compounds increases with increasing their concentration. The highest efficiency of ANB was $71 \%$ and for ACB $38 \%$. By using $A B$ and $A B C l$, no significant inhibition of CuNi alloy corrosion is achieved.

Studies conducted in time by electrochemical impedance spectroscopy show that, over time, corrosion protection offered by $A C B$ and $A N B$ increases due to the adsorption of studied molecules on the metal surface. FTIR spectroscopy confirmed adsorption of $A C B$ and ANB on CuNi surface.

\section{REFERENCES}

[1] X. Zhu, T. Lei, Corros. Sci. 2002, 44, 67.

[2] S. Martinez, M. Metikoš-Huković, J. Appl. Electrochem. 2006, 36, 1311.

[3] P. C.Dodds, G.Williams, J. Radcliffe, Prog. Org. Coatings 2017, 102, 107.

[4] A. E. Hughes, I. S. Cole, T. H. Muster, R. J. Varley, NPG Asia Mater. 2010, 2, 143.

[5] D. A.Winkler, M.Breedon, P.White, A. E.Hughes, E. D. Sapper, I. Cole, Corros. Sci. 2016, 106, 229.

[6] G. Gece, Corros. Sci. 2011, 53, 3873.

[7] M. M. Antonijević, M. B. Petrović, Int. J. Electrochem. Sci. 2008, 3, 1.

[8] H. Otmačić Ćurković, E. Stupnisek-Lisac, H. Takenouti, Corros. Sci. 2010, 52, 398.

[9] Z. Hajdari, H. Otmačić Ćurković, V. Čadež, S. Šegota, J. Electrochem. Soc. 2016, 163, C145.

[10] A. Fateh, A.R. Rezvanian, M. Aliofkhazraei, Arab. J. Chem. 2017, in press.

[11] I. B. Obot, U. M. Edouk, J. Mol. Liq. 2017, 246, 66.

[12] E. F. Silva, M. C. E. Bandeira, W. A. Alves, O. R. Mattos, J. Electrochem. Soc. 2018, 165, C375.

[13] M. Finšgar, I. Milošev, Corros. Sci. 2010, 52, 2737.

[14] M. M. Antonijević, S. M. Milić, M. B. Petrović, Corros. Sci. 2009, 51, 1228.

[15] H. Saifi, M.C. Bernard, S. Joiret, K. Rahmouni, H. Takenouti, B. Talhi, Mater. Chem. Phys. 2010, 120, 661.

[16] H. Otmačić, E. Stupnišek-Lisac, Electrochim. Acta 2003, 48, 985.

[17] M. B. Petrović Mihajlović, M. B. Radovanović, ž. Z. Tasić, M. M. Antonijević, J. Mol. Liq. 2017, 225, 127.

[18] K. Xhanari, M. Finšgar, New J. Chem. 2017, 41, 7151. 
[19] K. F. Khaled, Electrochim. Acta 2003,48, 2493.

[20] T. Yanardag, S. Özbay, S. Dinçer, A. A. Aksut, Asian J. Chem. 2012, 24, 47.

[21] P. Morales-Gil, G. Negron- Silva, M. Romero- Romo, C. Angeles- Chavez, M. Palomar Pardave, Electrochim. Acta 2004, 49, 4733.

[22] G. Lewis, Corros. Sci. 1982, 22, 579.

[23] E. Gutiérrez, Corros. Sci. 2016, 108, 23.

[24] Y. Bansal, O. Silakari, Bioorg. Med. Chem. 2012, 20, 6208.

[25] M. Cindrić, S. Jambon, A. Harej, S. Depauw, M. DavidCordonnier, S. Kraljević Pavelić, G. Karminski-Zamola, M. Hranjec, Eur. J. Med. Chem. 2017, 136, 468.

[26] M. Hranjec, I. Sović, I. Ratkaj, G. Pavlović, N. Ilić, L. Valjalo, K. Pavelić, S. Kraljević Pavelić, G. KarminskiZamola, Eur. J. Med. Chem. 2013, 59, 111.
[27] A. Ghanbari, M. M. Attar and M. Mahdavian, Mater. Chem. Phys. 2010, 124, 1205.

[28] A. K. Popova, M. S. Machkova, A. G. Djambova, A. Zwetanova, S. N. Raicheva, Bulg. Chem. Commun. 2008, 40, 300.

[29] A. Popova, M. Christov, S. Raicheva, E. Sokolova, Corros. Sci. 2004, 46, 1333.

[30] M. M. Kabanda, L. C. Murulana, M. Ozcan, F. Karadag, I. Dehri, I. B. Obot and E. E. Ebenso, Int. J. Electrochem. Sci. 2012, 7, 5035.

[31] M. Finšgar, B. Petovar, K. Xhanari, U. Maver, Corros. Sci. 2016, 111, 370.

[32] K. Starčević, I. Ćaleta, D. Cinčić, B. Kaitner, M. Kralj, K. Ester, G. Karminski-Zamola, Heterocycles 2006, 68, 2285. 